\title{
Descentralização e formação continuada de professores na RMC
}

\author{
Vicente Rodriguez ${ }^{*}$, Marcelo Vieira ${ }^{* *}$
}

Resumo: Novas formas institucionais para oferta de formação continuada de professores têm se apresentado na Regiāo Metropolitana de Campinas (RMC). Procuramos, com este artigo, compreender como se tem dado esse processo, considerando o contexto descentralizado das políticas públicas educacionais e os problemas de gestão pública brasileira e metropolitana. Investigando e analisando diversos índices da última década, como: evolução do número de professores, investimento e matrículas nos diversos níveis da educação básica e por instância administrativa, pudemos verificar determinados aspectos e reflexos dessas políticas, principalmente quando se trata de novas formas de arranjos entre o público e o privado. Percebemos o aumento da participação das diversas formas não estatais, incluindo o mercado, na oferta de formação continuada de professores e gestão educacional, entre outras formas não menos relevantes.

Palavras-chave: formação continuada de professores; descentralização; políticas públicas.

\section{Decentralization and teachers' continuous training in the metropolitan region of Campinas (RMC)}

Abstract: New institutional arrangements for the provisions of teachers continuous training has been performed in the Metropolitan Region of Campinas (RMC). In this article, we seek to understand how this process goes on, considerating the context for decentralized public policies and educational problems in Brazil and metropolitan governance. Investigating and examinating various indices of the lasted decade, like growth in the numbers of teachers, investments and enrollment at all levels of basic education and administrative level, we could verify certains aspects and consequences of these policies, especially when it comes to new forms of arrangements between public and private. It was noted the increased participation of various non-governmental forms, including the market in offering continuing education for teachers and educational administration as any other forms no less relevant to perform it.

Key words: teachers continuous education; decentralization; public policies.

\footnotetext{
* Professor do Departamento de Ciências Sociais na Educação (Decise) e membro do Grupo de Políticas Públicas e Educação da Faculdade de Educação - Unicamp, Campinas, SP, Brasil. virodri@unicamp.br.

** Professor do Departamento de Fundamentos da Educação da Universidade Federal de Santa Maria (UFSM), RS, Brasil. marcelo.pustilnik@ufsm.br.
} 


\section{Introdução}

Este artigo procura compreender as novas formas institucionais para oferta de formação continuada de professores, na Regiāo Metropolitana de Campinas (RMC), a partir da análise de alguns dados educacionais de 1999 a 2006, considerando a territorialização das políticas públicas educacionais e os problemas de gestão estatal local e metropolitana.

A reforma do Estado brasileiro, proposta no Plano da Reforma do Aparelho de Estado (Prade), de 21 de setembro de 1995, e implantado pelo Ministério da Administração Federal e Reforma do Estado (Mare), insere-se em um dos campos de discussão sobre a crise do Estado Capitalista no final do século XX1.

O Estado Capitalista contemporâneo vive os efeitos da globalização/mundialização em todas as suas dimensóes; no entanto, duas formas de pressáo operam como ameaças a sua própria reprodução: uma sobre suas fronteiras, pelo movimento exterior da livre circulação de ideias e mercadorias; e outra sobre a unidade nacional e política, pelas pressóes autonomistas locais. A descentralização, movimento integrante das pressões da globalização, compóe este quadro, e suas manifestaçóes precisam ser analisadas em cada componente (educação, saúde, economia, cultura), pois cada um se encontra determinado pelo seu desenvolvimento histórico e pelas disputas particulares ao campo em que está inserido.

O breve quadro esboçado a seguir tem como objetivo indicar o contexto no qual se desenvolve o processo que o artigo analisa. A resumida discussão pretende, apenas, destacar certos aspectos da problemática estatal-territorial na política educativa de formação continuada.

Esta nova conjuntura deu impulso a visóes que pregam o fim do Estado na sociedade contemporânea; alguns autores (Ohmae, 2006) observam a incapacidade crescente do Estado para controlar a economia e seu mercado de trabalho frente ao capital multinacionalizado e globalizado que impóe suas decisóes; por outro lado, destacam a crescente ineficácia da governabilidade de nível nacional diante dessas imposiçóes e de seu gerenciamento. "A tarefa do estado nação, e como a das municipalidades dentro do Estado sempre foi: fornecer a infraestrutura e os bens públicos que os negócios necessitam, pelo menor custo possível" (Hirst; Thompsom, 1998).

Apesar do seu apelo para a direita liberal e para a esquerda tradicional, esse vaticínio é inconsistente historicamente. O Brasil foi permeável a esses argumentos no início dos anos 1990, no governo Collor de Melo, 1990-1992, e manteve-se vigoroso no primeiro mandato de Fernando Henrique Cardoso (FHC), 19941998. A efetivação da reforma do Estado (Mare), com a Emenda Constitucional

I Esta discussão extensa e controversa não constitui objeto deste texto, mas pode ser acompanhada pela literatura nacional e internacional. Claus Offe, M Castells, A Guiddens, T. Adrião, V. Peroni e L.C. Bresser-Pereira podem colaborar nesta discussão.

Pro-Posiçōes, Campinas, v. 23, n. 2 (68), p. 67-90, maio/ago. 2012 
(EC) nº19, de 04 de junho de 1998 (Brasil, 1998), já se realizou sob o auspício da necessidade de um estado forte e eficaz gerencialmente, sendo possíveis ambas as condiçóes unicamente se o Estado sofresse um choque democrático pela incorporaçâao da sociedade civil ao seu funcionamento (Bresser-Pereira, 1999). A partir de 2002 essa tese tornou-se dominante, com a proposta de um desenvolvimento nacional com forte apoio popular, no governo Lula.

A proposta do governo pretendeu administrar essa crise com os seguintes pressupostos:

a) Enfrentar a questão fiscal, racionalizando e reduzindo o gasto público de forma seletiva e não de forma geral (distanciando-se do neoliberalismo).

b) Opor-se a soluçôes estatizantes, ante o fracasso das teses propostas pelo desenvolvimentismo, pelo populismo latino-americano ou das propostas pró-soviéticas.

c) Alterar o modelo gerencial e administrativo burocrático, aproximando essas atividades públicas do modelo gerencial de mercado.

d) Democratizar o Estado pela incorporação da sociedade civil na gestão e no provimento de serviços em áreas definidas como públicas náo estatais.

Essas reformas ainda repercutem no sistema educativo na oferta de cobertura e nas formas de desenvolvimento da educação, particularmente no desenvolvimento profissional dos docentes; a Formação Continuada de Professores (FCP) revela-se especialmente sensível a essas reformas.

O Estado continua tendo um papel central na governabilidade social nacional na atual conjuntura, e os questionamentos quanto às mudanças impostas pela mundialização do capital não contradizem esse papel². Durante muitas décadas, os limites de mobilidade das pessoas e as dificuldades de globalizar as pessoas e as naçóes garantiram ao Estado uma função destacada na condução do governo social e na sustentação dos acordos internacionais. No entanto, no Brasil, o Estado existente em 2010 era substancialmente diferente daquele do início dos anos 1990; a política pública, em todas as áreas: econômica, social e cultural, passou por transformações substanciais no período; e o "estado em ação" exigiu conceitos diferentes para poder ser conhecido e pesquisado. A política de descentralização do Estado brasileiro, em desenvolvimento desde o início dos anos 80, tem grande responsabilidade por essa mudança ${ }^{3}$. No contexto descentralizado, a ação pública estatal redefine suas formas de intervenção.

O objetivo deste artigo é refletir sobre as formas institucionais e políticas (atores) da ação estatal na Formação Continuada de Professores. Sobressai, nas

2 Ver, para esta discussão, Hirst e Thompson (1998, p. 274).

3 A descentralização em direção ao mercado pelas privatizações retiraram do Estado mecanismos poderosos da condução macroeconômica do País. As parcerias público-privado podem representar o enfraquecimento dos mecanismos de condução da governabilidade social. 
primeiras análises, o crescimento do setor privado; no entanto, existem pesquisas em andamento ${ }^{4}$ que exploram essa discussão, permitindo centrar nossos objetivos prioritariamente nas respostas do setor público estatal. A resposta pública estatal na área educacional foi a política social mais sensível à incorporação da sociedade para garantir sua oferta ou sua gestão. Sob as mais diversas formas, ONGs, empresas, mecanismos de participação na gestáo e formas de parceria público-privado tomaram novos contornos na área educacional nos últimos 20 anos. O setor do sistema educativo, que foi descentralizado no período - os sistemas municipais de ensino - é o espaço onde esta experiência se encontra em desenvolvimento. A Formação, como em outros países, encaminha-se para ser assumida como responsabilidade do mercado; ao menos para o suprimento da oferta, restando ao Estado o financiamento da política.

\section{Descentralização da política educacional}

O Brasil implementou, a partir de meados dos anos 1990, um dos processos de descentralização educacional mais significativos do continente latino-americano. Essencialmente um processo de municipalização das matrículas, entre 1999 e 2006 mais de 5 milhóes delas foram transferidas de outras instâncias administrativas para o município. Esse processo, combinado com as características específicas assumidas pelo federalismo brasileiro, pós-Assembleia Constituinte de $1988^{5}$, teria várias consequências para o sistema educativo do País. Consequências que refletiram na qualidade do processo de ensino-aprendizagem, na qualidade das condiçóes institucionais e dos recursos humanos do sistema.

Entre 1999 e 2006, houve uma transferência de competências educacionais dos entes centrais do sistema para os poderes locais e em direçáo à sociedade (mercado, sociedade civil), coincidindo com a dinâmica estabelecida para os processos de descentralização política e administrativa do Estado no capitalismo contemporâneo globalizado. A distribuição de recursos por unidade federada no período mostra a expansão do nível municipal e a retração dos Estados e da União (ver Gráfico 1).

A transferência de matrículas para o nível local, no período analisado, alcançou os 9 milhóes de alunos (ver Gráfico 2). Dessa forma, pode-se afirmar que o nível municipalizado assumiu a centralidade do sistema de educação básica.

4 Borghi e Adrião vêm desenvolvendo essa pesquisa com apoio da Fapesp (Adrião; Peroni, 2008).

5 A Constituição instituiu o município como ente pleno da federação, com autonomia política e financeira, tornando o Brasil uma das federações mais descentralizadas do mundo.

Pro-Posições, Campinas, v. 23, n. 2 (68), p. 67-90, maio/ago. 2012 
Gráfico I - Gasto com educação pública por esfera de governo, em valores constantes - 1995-2005

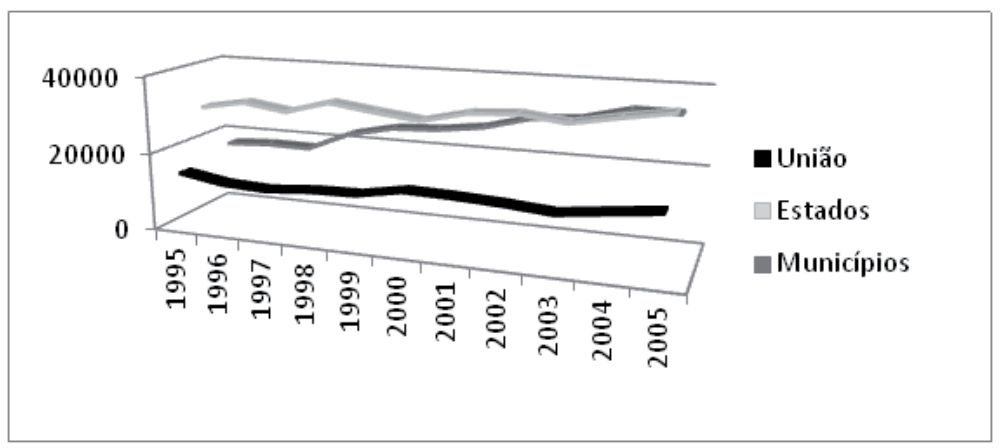

Fonte: Abrahão (2005). Elaborado pelos autores.

Gráfico 2 - Matrículas da educação pública por esfera de governo 1995-2005

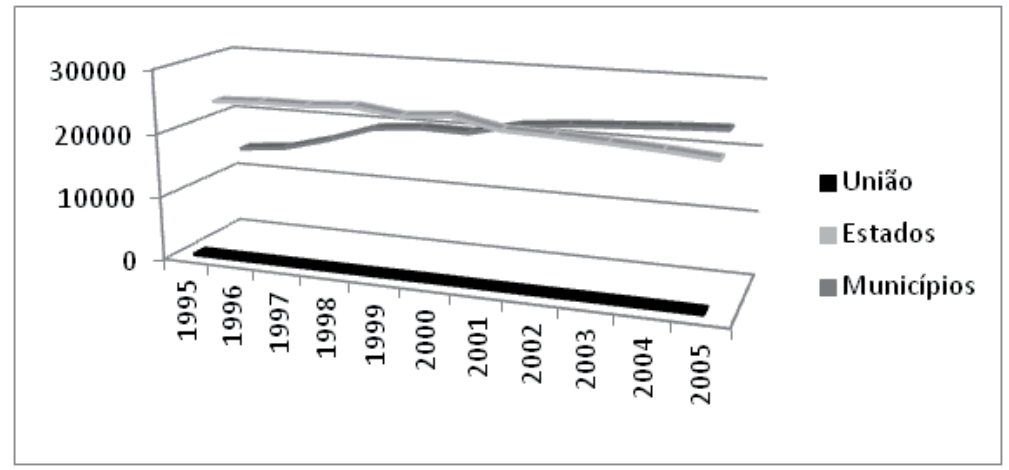

Fonte: Abrahão (2005). Elaborado pelos autores.

Este processo de descentralização, cristalino nos seus números, resulta mais complexo nos seus efeitos federativos, em primeiro lugar, pois no seu contexto geral, o processo federativo brasileiro, de 1994 para frente, vem apresentando, concomitantemente, um processo de "recentralização" e fortalecimento do nível federal sobre os outros, com a recomposição dos recursos fiscais e financeiros da União e dos recursos políticos (legitimidade) da presidência eleita de forma direta. Isso se torna evidente em todos os níveis de atuação do Estado brasileiro, inclusive nas políticas sociais mais descentralizadas durante o período.

Em segundo lugar, a partir de 1998, com a reforma do Mare, o setor privado - a sociedade - passou a desenhar um novo perfil na relação público-privado na formação social e econômica brasileira. A política de democratização do Estado, 
através de um "choque de sociedade civil" nas suas atividades ${ }^{6}$, alterou também as relaçôes da federação brasileira no século XXI. Dessa forma, com uma federação com maior concentraçáo de poder na União, combinado com uma maior presença do privado (mercado e comunidade), colocam-se em questáo os fins mesmos da política educacional no Brasil.

Justamente nesse cenário descentralizador é que iremos tentar compreender no contexto educacional a formação continuada de professores. Existe um consenso entre os estudiosos quanto ao papel central do professor para recuperar a qualidade da educaçáo no Brasil. A seguir serão apresentadas algumas análises sobre o comportamento desse segmento na federação.

\section{3. $\bigcirc$ professor brasileiro}

A evolução e a distribuição dos docentes entre 1999 e 2006, segundo o censo do professor, teve o seguinte comportamento nesse período: em 1999, o Brasil possuía 2.338.863 professores em todos os níveis do ensino básico e em todas as instâncias administrativas. Em 2006, eram 2.908.873 - 570.010 a mais no sistema, representando um crescimento de $24,40 \%$ no período.

Tabela I — Professores da Educação Básica por instância e nível de ensino no Brasil - 1999 a 2006

\begin{tabular}{|r|r|r|r|r|r|r|r|r|r|}
\hline Ano & $\begin{array}{r}\text { Depend. } \\
\text { Administ. }\end{array}$ & $\begin{array}{r}\text { Leciona } \\
\text { em } \\
\text { creche }\end{array}$ & $\begin{array}{c}\text { Leciona } \\
\text { em pré- } \\
\text { escola }\end{array}$ & $\begin{array}{r}\text { Leciona } \\
\text { em classe } \\
\text { de alfab. }\end{array}$ & $\begin{array}{c}\text { Leciona } \\
\text { no Ens. } \\
\text { Fundam. }\end{array}$ & $\begin{array}{c}\text { Leciona } \\
\text { no Ens. } \\
\text { Médio }\end{array}$ & $\begin{array}{c}\text { Leciona } \\
\text { na EJA }\end{array}$ & $\begin{array}{l}\text { Leciona } \\
\text { na Educ. } \\
\text { Especial }\end{array}$ & Totais \\
\hline 1999 & Estadual & 919 & 15.937 & 1.441 & 626.744 & 259.671 & 58.013 & 11.888 & 974.613 \\
\hline 1999 & Federal & 39 & 81 & 53 & 2.091 & 11.834 & 156 & 246 & 14.500 \\
\hline 1999 & Municipal & 28.570 & 126.288 & 23.874 & 638.516 & 16.827 & 27.668 & 6.597 & 868.340 \\
\hline 1999 & Privada & 18.756 & 71.817 & 15.785 & 219.941 & 112.825 & 21.654 & 20.632 & 481.410 \\
\hline 1999 & Total & 48.284 & 214.123 & 41.153 & 1.487 .292 & 401.157 & 107.491 & 39.363 & 2.338 .863 \\
\hline 2000 & Estadual & 918 & 14.316 & 964 & 628.479 & 290.682 & 65.649 & 12.038 & 1.013 .046 \\
\hline 2000 & Federal & 40 & 84 & 65 & 2.188 & 11.682 & 172 & 241 & 14.472 \\
\hline 2000 & Municipal & 28.370 & 138.319 & 25.636 & 684.739 & 15.429 & 35.941 & 7.474 & 935.908 \\
\hline 2000 & Privada & 20.896 & 75.616 & 15.617 & 222.605 & 112.674 & 20.937 & 21.233 & 489.578 \\
\hline 2000 & Total & 50.224 & 228.335 & 42.282 & 1.538 .011 & 430.467 & 122.699 & 40.986 & 2.453 .004 \\
\hline 2001 & Estadual & 1.057 & 14.075 & 564 & 614.635 & 312.124 & 74.693 & 11.818 & 1.028 .966 \\
\hline 2001 & Federal & 122 & 135 & 76 & 2.266 & 9.455 & 172 & 222 & 12.448 \\
\hline 2001 & Municipal & 34.810 & 150.882 & 24.620 & 709.556 & 14.568 & 56.173 & 7.714 & 998.323 \\
\hline 2001 & Privada & 27.040 & 83.540 & 15.785 & 226.724 & 112.422 & 21.264 & 22.887 & 509.662 \\
\hline 2001 & Total & 63.029 & 248.632 & 41.045 & 1.553 .181 & 448.569 & 152.302 & 42.641 & 2.549 .399 \\
\hline
\end{tabular}

6 Proposta delineada por A. Guiddens para o programa de uma terceira via para enfrentar a crise das sociedades capitalistas atuais. Ver Guiddens (2007). 


\begin{tabular}{|c|c|c|c|c|c|c|c|c|c|}
\hline Ano & $\begin{array}{l}\text { Depend. } \\
\text { Administ. }\end{array}$ & $\begin{array}{c}\text { Leciona } \\
\text { em } \\
\text { creche }\end{array}$ & $\begin{array}{l}\text { Leciona } \\
\text { em pré- } \\
\text { escola }\end{array}$ & $\begin{array}{l}\text { Leciona } \\
\text { em classe } \\
\text { de alfab.* }\end{array}$ & $\begin{array}{l}\text { Leciona } \\
\text { no Ens. } \\
\text { Fundam. }\end{array}$ & $\begin{array}{l}\text { Leciona } \\
\text { no Ens. } \\
\text { Médio }\end{array}$ & $\begin{array}{c}\text { Leciona } \\
\text { na EJA }\end{array}$ & $\begin{array}{l}\text { Leciona } \\
\text { na Educ. } \\
\text { Especial }\end{array}$ & Totais \\
\hline 2002 & Estadual & 1.142 & 13.905 & 535 & 606.542 & 331.054 & 87.785 & 12.125 & 1.053 .088 \\
\hline 2002 & Federal & 109 & 147 & 67 & 2.152 & 8.272 & 125 & 218 & 11.090 \\
\hline 2002 & Municipal & 37.499 & 158.662 & 22.278 & 738.913 & 13.459 & 71.425 & 8.461 & 1.050 .697 \\
\hline 2002 & Privada & 30.140 & 86.489 & I5.40I & 233.437 & 115.525 & 21.663 & 23.686 & 526.341 \\
\hline 2002 & Total & 68.890 & 259.203 & 38.281 & 1.581 .044 & 468.310 & 180.998 & 44.490 & 2.641 .216 \\
\hline 2003 & Estadual & 1.218 & 14.222 & 549 & 599.060 & 353.129 & 108.369 & 12.276 & I.088.823 \\
\hline 2003 & Federal & 109 & 146 & 55 & 2.342 & 7.407 & 99 & 226 & 10.384 \\
\hline 2003 & Municipal & 40.568 & 166.243 & 21.818 & 763.751 & 12.648 & 84.332 & 9.369 & 1.098 .729 \\
\hline 2003 & Privada & 32.870 & 89.964 & 15.086 & 238.698 & 115.192 & 20.768 & 24.948 & 537.526 \\
\hline 2003 & Total & 74.765 & 270.575 & 37.508 & 1.603 .851 & 488.376 & 213.568 & 46.819 & 2.735 .462 \\
\hline 2004 & Estadual & 1.005 & 13.167 & 0 & 589.501 & 367.192 & 124.738 & 12.404 & I.108.007 \\
\hline 2004 & Federal & 101 & 162 & 0 & 2.149 & 6.690 & 72 & 224 & 9.398 \\
\hline 2004 & Municipal & 41.143 & 182.002 & 0 & 787.772 & 11.200 & 94.420 & 10.777 & I.125.314 \\
\hline 2004 & Privada & 33.026 & 98.368 & 0 & 243.986 & 113.120 & 18.973 & 26.675 & 534.148 \\
\hline 2004 & Total & 75.275 & 293.699 & 0 & 1.623 .408 & 498.202 & 236.203 & 50.080 & 2.776 .867 \\
\hline 2005 & Estadual & I.44I. & $|2.02|$ & 0 & 576.601 & $374.94 I$ & 131.619 & 12.125 & I. 108.748 \\
\hline 2005 & Federal & 134 & 156 & 0 & 2.330 & 6.482 & 122 & 239 & 9.463 \\
\hline 2005 & Municipal & 49.056 & 197.045 & 0 & 807.456 & 11.054 & 99.504 & 10.704 & 1.174 .819 \\
\hline 2005 & Privada & 35.701 & 100.122 & 0 & 248.175 & 115.946 & 16.738 & 27.941 & 544.623 \\
\hline 2005 & Total & 86.332 & 309.344 & 0 & 1.634 .562 & 508.423 & 247.983 & 51.009 & 2.837 .653 \\
\hline 2006 & Estadual & 1.301 & 11.164 & 0 & 582.412 & 385.258 & $|42.82|$ & 13.090 & I.136.046 \\
\hline 2006 & Federal & 134 & 142 & 0 & 2.277 & 6.530 & 266 & 272 & 9.621 \\
\hline 2006 & Municipal & 56.442 & 201.068 & 0 & 828.925 & 11.835 & 107.358 & 12.307 & 1.217 .935 \\
\hline 2006 & Privada & 36.161 & 97.507 & 0 & 251.727 & 116.312 & 14.608 & 28.956 & 545.271 \\
\hline 2006 & Total & 94.038 & 309.881 & 0 & 1.665 .341 & 519.935 & 265.053 & 54.625 & 2.908 .873 \\
\hline
\end{tabular}

* É importante esclarecer que, após 2004, as classes de alfabetização foram incorporadas ao Ensino Fundamental, passando seus professores a atuar neste nível de ensino.

Fonte: Brasil (2006a). Elaborado pelos autores.

Esse crescimento se distribui de forma desigual entre os níveis de ensino; assim, o nível com maior expansão de professores foi a Educação Infantil (53,92\%), em que a creche teve um crescimento de $94,8 \%$, o maior entre todos os níveis. A Educação Pré-escolar apresentou crescimento importante, de 44,72\%. Ajudam a explicar esse crescimento, entre outros motivos, o baixo patamar de cobertura deste nível de ensino durante a década de 1990 e a maior pressão dos movimentos sociais e suas organizações, que obtiveram importantes conquistas político-institucionais nos anos 2000. Deve-se destacar que, junto com a pressão do mercado de trabalho pela incorporação de mão de obra feminina - o que leva a mulher a exigir escolarização para seus filhos em idade pré-escolar -, é de grande importância o fato de este nível 
de ensino ser totalmente municipalizado. Isso permite uma pressão maior no confronto entre poder público e movimentos sociais, por suas repercussóes eleitorais imediatas. Não menos importante será verificar o peso da unidade administrativa para programar e gerenciar as respostas educativas.

O Ensino Fundamental, o de maior impacto nas políticas de descentralização, teve um crescimento mais modesto, de 12,0\%. Apesar da expansão da cobertura deste nível de ensino no período, dois fenômenos contribuem para explicar o menor crescimento na demanda de professores: as políticas públicas de regulação de fluxo escolar e, principalmente, a significativa queda nas taxas de crescimento populacional no Brasil. No Ensino Médio, o crescimento foi de 29,60\%; vale destacar que este nível foi principalmente de responsabilidade dos estados.

Ao aprofundar a análise das instâncias administrativas, o setor municipalizado revela-se o de maior expansáo; no entanto, cabe ressaltar o crescimento do setor privado no período: $92,80 \%$, sustentado pela expansão da cobertura educacional de alguns níveis educativos (o pré-escolar e o Ensino Superior) e assentado na expansão do setor mercantil e comunitário por meio de uma política de parcerias público-privado.

\section{I. O perfil do professor brasileiro}

Em 2003, o Inep realizou o segundo censo de professores no Brasil. Após a coleta dos formulários e sistematizadas as informações, estas resultaram em um total de 247 variáveis de dados por professor. Em relaçáo à taxa de resposta, de um total de 2.497.918 de Profissionais do Magistério da Educação Básica (Pmeb), foram respondidos 1.542 .878 formulários, resultando em uma taxa de resposta de $61,8 \%$, cobrindo $75 \%$ das escolas do País. Como a pesquisa era censitária, não há como definir o erro da amostra; o Inep (Brasil, 2006a) chama a atenção para que se tomem os devidos cuidados, ao fazer a análise desses dados, principalmente os centrais de média e mediana.

Por essas razóes, os resultados ora mostrados nesta publicação devem ser interpretados com cautela e relativizados, ao realizarmos inferências ou generalizaçóes dos resultados. Não conhecemos o perfil dos profissionais que não responderam à pesquisa. Como não houve um delineamento amostral prévio, pois o intuito era a coleta censitária, não nos é permitido, sequer, calcular o erro das estimativas. (Brasil, 2006a, p. 10)

Sem dúvidas, independentemente desse importante aspecto, os dados nos mostram informaçóes valiosas, que nos permitem traçar um perfil geral dos Pmeb do Brasil. Podemos observar, pelo Gráfico 3 - Distribuição do Número de Pmeb 
por Sexo, que se trata de uma profissão feminina, com $85 \%$ de mulheres atuando na Educação Básica.

\section{Gráfico 3 - Distribuição do número de Pmeb por sexo}

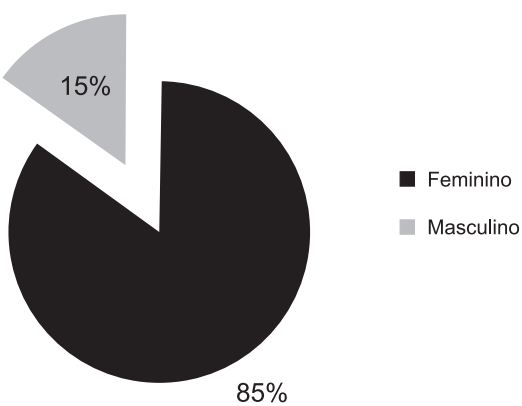

Fonte: Brasil (2006b)

A idade média dos Pmeb está situada acima dos 35 anos, conforme demonstra o Gráfico 4, apesar de ser significativa a presença de profissionais entre 18 e 34 anos.

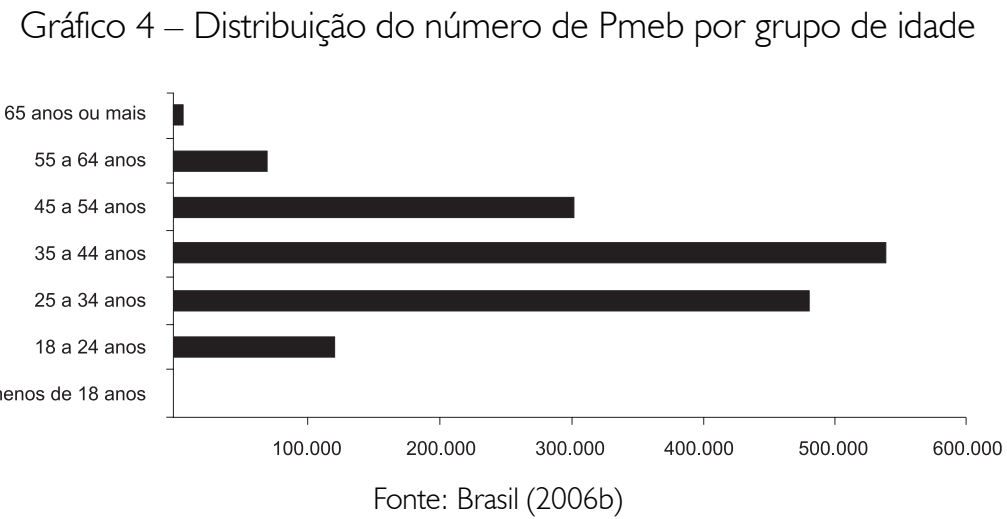

Quanto ao salário, o cálculo da mediana do salário ${ }^{7}$ dos profissionais da educação indica que, em setembro de 2003 , o valor era de $\mathrm{R} \$ 648,00$ para mulheres e de $\mathrm{R} \$ 719,00$ para homens, lembrando que as mulheres são maioria absoluta, e as oportunidades de salários mais altos sáo mais restritas; a mediana tende a ser me-

7 Valores do salário bruto (sem descontos), incluindo as gratificações referentes ao mês de setembro de 2003. Não foi considerada a carga horária. 
nor neste grupo. Isso pode também ser um indicador das desigualdades de gênero existentes no País, em que os cargos com salários mais altos são prioritariamente masculinos, pois, muitas vezes, mesmo dentro da mesma função, os homens recebem salários maiores. Um indicador dos baixos salários desta profissão está no valor de ganho para fazer parte dos 30\% mais bem pagos: entrava neste grupo o Pmeb, as mulheres que ganhavam mais que $\mathrm{R} \$ 975,00$ e os homens que recebiam acima de $\mathrm{R} \$ 1.100,00$. Na faixa dos salários mais altos, somente $1 \%$ - entre homens e mulheres - ganhava mais que $\mathrm{R} \$ 4.500,00$.

No Gráfico 5 - Pmeb por grau de formação, pode-se observar que a grande maioria possui nível superior com licenciatura, mas ainda há um número significativo de profissionais que só possuem formação em magistério em nível médio. Em menor número, estão os professores sem licenciatura e aqueles que sequer possuem magistério em nível médio, tendo alguns deles concluído o Ensino Médio e outros, apenas o Ensino Fundamental.

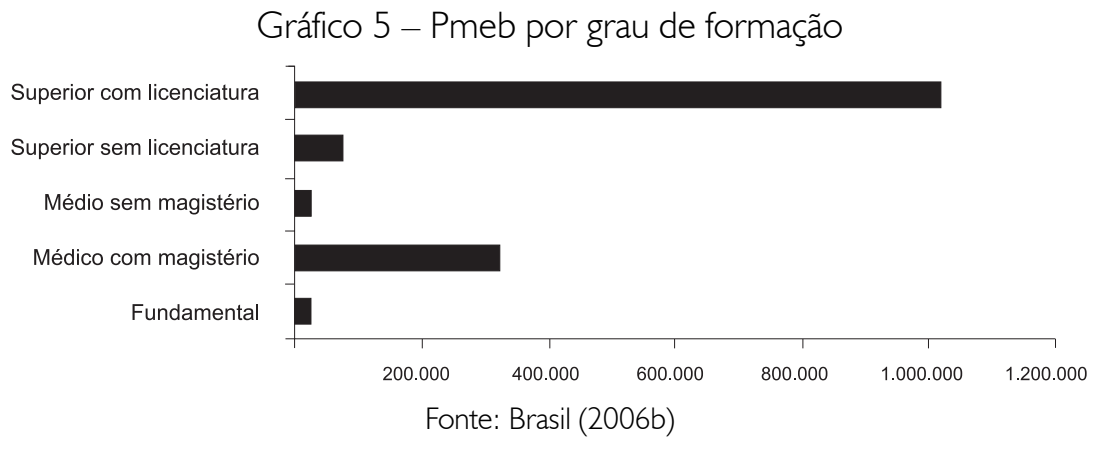

Todos esses professores, mais de 400 mil, com formação em nível superior, mas sem licenciatura, ou aqueles sem formação em nível superior são hoje os clientes dos cursos de formação inicial em exercício, ou seja, cursos de formaçáo continuada com enfoque na formação inicial.

\subsection{O professor em contexto descentralizado}

No Brasil, o professor descentralizado adquire, em termos quase gerais, uma característica comum: inscreve-se institucionalmente em estruturas débeis ou muito recentes e, na sua grande maioria, sem condiçôes de oferecer formação e carreira para o magistério, duas condiçóes fundamentais para incentivar o desenvolvimento do professor e, assim, garantir a qualidade de ensino diante das transformaçôes das sociedades capitalistas atuais (Imbernón, 2009).

Ganha maior dimensão este problema, se o confrontamos com os diagnósticos e as propostas mais consensuais para enfrentar as dificuldades educacionais contem- 
porâneas e globais (Garcia, 1999). Todas as propostas provenientes de organizaçóes internacionais, governamentais ou de movimentos sociais outorgam ao docente um papel central na transformação do sistema educativo, porém, assinalam que sua concreção está condicionada por uma série de desafios .

Assim, a descentralização, se, por um lado, desencadeia um processo de desenvolvimento institucional dos poderes locais, sacrifica a esse processo os resultados da mudança educativa, no que se refere à qualidade de ensino. Os municípios, 15 anos após iniciada a descentralização, procuram ainda estabelecer as condiçóes mínimas para o desenvolvimento profissional docente, especificamente: implantar plano de carreira, observar o estatuto do magistério e adotar modelos de formação continuada para os docentes. Não seria temerário associar o sucesso da expansão do sistema educativo e a baixa qualidade do ensino à demora dos órgãos de governo, em todas as instâncias da federação, para alterar e tornar efetivos os sistemas de formação e desenvolvimento profissional do professor.

A esse fenômeno, a fragilidade institucional, algumas pesquisas associam a expansão do setor mercantil no fornecimento de serviços educacionais (Adriáo; Peroni, 2008). Deve ser acrescentada, apenas, a esta análise, a irrupção do setor não mercantil (ONGs e outras), assumindo maiores funções na expansão de vagas e no desenvolvimento gerencial e profissional do sistema público estatal.

Em 1999, o total de professores atuando em todos os níveis de ensino, na RMC, era de 78.182, tendo passado para 104.857 em 2006. Isso representa um crescimento de $34,12 \%$ no período, bem superior ao crescimento nacional (ver Tabela 2).

A seguir, procede-se à analise dessa expansão, do número de professores por nível de ensino e dependência administrativa, numa tentativa de descrever o padrão para o comportamento do nível descentralizado, no Brasil, numa região particular.

$\mathrm{Na}$ Tabela 3, percebe-se que o crescimento de professores de creche, na RMC, foi de 86,0\%, entre 1999 e 2006, destacadamente o maior entre os níveis de ensino. A explicação para a situação nacional corresponde também ao nível local. No entanto, essa expansão fica abaixo da taxa nacional do nível, que foi de $94,8 \%$ para o Brasil.

Os professores da pré-escola regional cresceram 39,1\% no período, taxa inferior à nacional, de 44,7\%. Já no Ensino Fundamental, o crescimento de 28,2 \% superou a taxa nacional, de apenas $12 \%$.

Esses números informam que a expansão se realizou, na RMC, um pouco abaixo da média nacional de crescimento no nível das creches e na educação préescolar e bem acima, no Ensino Fundamental. O setor descentralizado apresentou, ainda assim, a principal responsabilidade na política de expansão do número de professores no sistema educativo regional. Esse ritmo no crescimento regional pode indicar as particularidades de renda e incorporação da mão de obra feminina 
na RMC; pode significar, também, a existência de uma rede mais preparada para suportar as pressões por políticas de cobertura desses níveis de ensino na Regiáo. Deve-se destacar, insistentemente, nessa expansão no âmbito regional, o peso do setor privado, bem acima do âmbito nacional.

Dada a expansão do setor privado mercantil e não lucrativo, apresenta-se, a seguir, uma análise do comportamento da rede privada, que se manifesta de forma diferente na RMC, segundo o nível educacional (ver Tabela 4). O número de professores de creches privadas cresceu 92,8\% no Brasil e 101,3\% no estado de Sáo Paulo, para atingir significativos $141,4 \%$ na RMC. O número de professores de pré-escola cresceu 35,8\% no Brasil, 64,1\% em SP e 57,5\% na RMC. No Ensino Fundamental, o crescimento foi de 14,5\% no País; em São Paulo, 22,9\%; e 28,6 $\%$ na RMC.

Tabela 2 - Total de professores por município - RMC - 1999-2006

\begin{tabular}{|c|c|c|c|c|c|c|c|c|c|}
\hline Município & 1999 & 2000 & 2001 & 2002 & 2003 & 2004 & 2005 & 2006 & $\begin{array}{c}\text { Evolução } \\
\text { (\%) }\end{array}$ \\
\hline Americana & 6.992 & 6.915 & 7.287 & 6.821 & 7.578 & 7.585 & 7.502 & 7.733 & 10,60 \\
\hline $\begin{array}{l}\text { Artur } \\
\text { Nogueira }\end{array}$ & 982 & 1.056 & 1.091 & 1.281 & 1.208 & 1.319 & 1.455 & 1.535 & 56,31 \\
\hline Campinas & 31.706 & 32.668 & 33.644 & 34.801 & 35.277 & 36.174 & 38.122 & 39.478 & 24,51 \\
\hline Cosmópolis & 1.649 & 1.685 & 1.683 & 1.732 & 1.726 & 1.831 & 1.995 & 2.115 & 28.26 \\
\hline $\begin{array}{l}\text { Engenheiro } \\
\text { Coelho }\end{array}$ & 345 & 306 & 393 & 409 & 452 & 495 & 526 & 574 & 66,38 \\
\hline Holambra & 407 & 402 & 425 & 463 & 474 & 526 & 549 & 617 & 51,60 \\
\hline Hortolândia & 4.196 & 4.810 & 5.089 & 5.788 & 6.059 & 6.525 & 6.956 & 7.383 & 75,95 \\
\hline Indaiatuba & 5.337 & 6.087 & 6.182 & 6.080 & 6.766 & 6.903 & 7.269 & 6.983 & 30,84 \\
\hline Itatiba & 3.161 & 3.628 & 3.688 & 3.471 & 3.727 & 4.146 & 3.963 & 4.073 & 28,85 \\
\hline Jaguariúna & 1.158 & 1.097 & 1.139 & 1.267 & 1.378 & 1.645 & 1.748 & 1.964 & 69,60 \\
\hline Monte Mor & 1.265 & 1.545 & 1.599 & 1.699 & 1.975 & 1.998 & 1.943 & 2.600 & 105,53 \\
\hline $\begin{array}{l}\text { Nova } \\
\text { Odessa }\end{array}$ & 1.510 & 1.557 & 1.587 & 1.581 & 1.816 & 1.830 & 1.862 & 1.950 & 29,14 \\
\hline Paulínia & 2.557 & 2.456 & 2.376 & 2.594 & 2.638 & 3.366 & 3.918 & 4.150 & 62,30 \\
\hline Pedreira & 1.032 & 1.130 & 1.117 & 1.227 & 1.333 & 1.316 & 1.321 & 1.437 & 39,24 \\
\hline $\begin{array}{l}\text { Santa } \\
\text { Bárbara } \\
\text { D'Oeste }\end{array}$ & 5.112 & 5.810 & 5.643 & 5.437 & 6.158 & 6.091 & 6.346 & 6.777 & 32,57 \\
\hline $\begin{array}{l}\text { Santo } \\
\text { Antonio de } \\
\text { Posse }\end{array}$ & 515 & 580 & 623 & 578 & 625 & 623 & 710 & 696 & 35,15 \\
\hline Sumaré & 5.379 & 6.408 & 6.385 & 6.927 & 7.421 & 7.588 & 7.775 & 8.474 & 57,54 \\
\hline Valinhos & 2.872 & 2.913 & 3.624 & 3.736 & 3.735 & 3.822 & 3.927 & 4.014 & 39,76 \\
\hline Vinhedo & 2.007 & 2.012 & 2.216 & 2.253 & 2.214 & 2.181 & 2.288 & 2.304 & 14,80 \\
\hline Total & 78.182 & 83.065 & 85.791 & 88.145 & 92.560 & 95.964 & 100.175 & 104.857 & 34,12 \\
\hline
\end{tabular}

Fonte Brasil (2006a). Elaborada pelos autores. 
Tabela 3 - Crescimento total de professores por

nível de ensino - 1999-2006 (\%)

\begin{tabular}{|l|r|r|r|}
\hline \multicolumn{1}{|c|}{ Nível de Ensino } & \multicolumn{1}{|c|}{ Totais Brasil } & Totais Estado SP & \multicolumn{1}{c|}{ Totais RMC } \\
\hline Creche & 94,8 & 104,5 & 86,0 \\
\hline Pré-escola & 44,7 & 43,1 & 39,1 \\
\hline Fundamental & 12,0 & 23,2 & 28,2 \\
\hline Médio & 29,6 & 15,6 & 25,1 \\
\hline
\end{tabular}

Fonte: Brasil (2006a). Elaborada pelos autores.

Tabela 4 - Crescimento de total de professores por rede: rede privada — 1999-2006

\begin{tabular}{|l|r|r|r|}
\hline Nível de Ensino & \multicolumn{1}{|c|}{$\begin{array}{c}\text { Totais: } \\
\text { Rede Privada no } \\
\text { Brasil }\end{array}$} & $\begin{array}{c}\text { Totais } \\
\text { Rede Privada no } \\
\text { Estado SP }\end{array}$ & $\begin{array}{c}\text { Totais } \\
\text { Rede Privada na } \\
\text { RMC }\end{array}$ \\
\hline Creche & 92,8 & 101,3 & 141,4 \\
\hline Pré-escola & 35,8 & 64,1 & 57,5 \\
\hline Fundamental & 14,5 & 22,9 & 28,6 \\
\hline Médio & 3,1 & $(4,1)$ & $(8,1)$ \\
\hline
\end{tabular}

Fonte: Brasil (2006a). Elaborada pelos autores.

$\mathrm{Na}$ RMC, o setor privado cresceu com vigor em todos os níveis de ensino (à exceção do Ensino Médio), tendo uma expansâo superior, como setor, em relaçáo ao crescimento total. Tanto o estado quanto os municípios apresentaram uma expansão explosiva do setor privado na creche e na pré-escola. No Ensino Fundamental, o setor privado cresceu, acompanhando o crescimento total na regiáo.

Uma análise mais acurada da evolução da expansão docente em nível nacional e regional permite destacar o impacto do Fundeb $^{8}$ na reversão da tendência nos anos 2000. Segundo o Gráfico 6, após a implantação do Fundeb, os municípios no Brasil passaram a contratar mais professores, enquanto o setor privado, apesar de continuar crescendo, já não acompanhou com o mesmo vigor.

Já na RMC, há uma situação mais relevante: o setor privado, que, a partir de 2000, vinha sendo predominante na regiáo, após o Fundeb, apresentou um decrescimento, enquanto o municipal retomou a dianteira na contratação. Assim revela o Gráfico 7.

8 O Fundeb corrige o Fundef, incorporando o ensino infantil no Ensino Básico e permite incluir as despesas com esse nível de ensino nos repasses do novo fundo.

Pro-Posiçóes, Campinas, v. 23, n. 2 (68), p. 67-90, maio/ago. 2012 
Gráfico 6 - Evolução de professores nas redes municipais e privadas no Brasil - 1999-2006

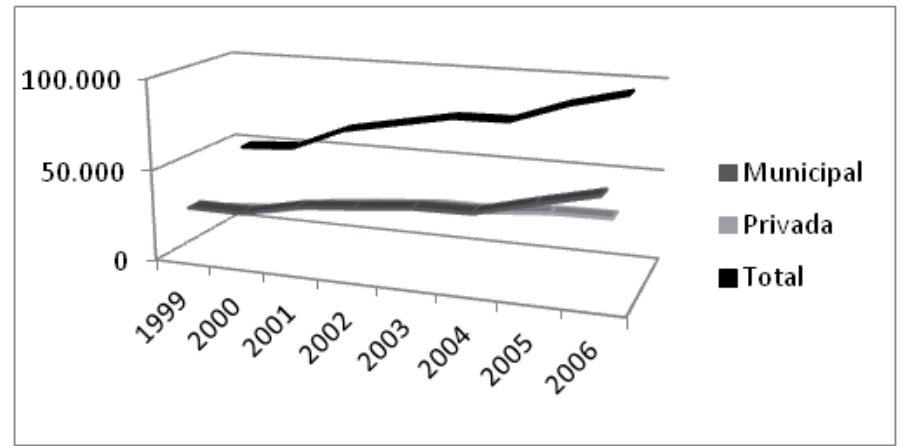

Fonte: Brasil (2006a). Elaborado pelos autores.

Gráfico 7 - Evolução de professores nas redes municipais e privadas na RMC - 1999-2006

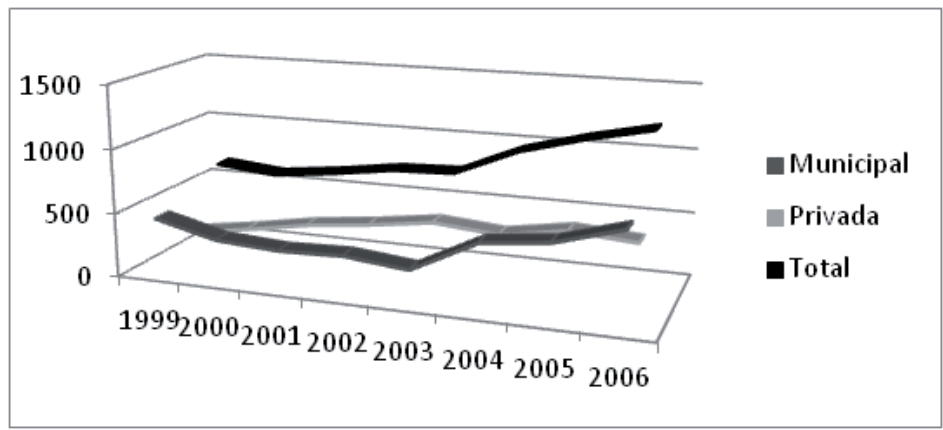

Fonte: BRASIL (2006a). Elaborado pelos autores.

\section{A Formação Continuada na RMC}

As pesquisas na região informam que os municípios apresentaram um modelo de oferta centrado no professor individual e na transmissão de conhecimento. Do ponto de vista de tipo de oferta de cursos, estes se apresentam pulverizados tematicamente e desarticulados curricularmente. Esse modelo individualizado, transmissivo, pulverizado e desarticulado tem sido objeto de pesadas críticas pelos especialistas em formação continuada. Alguns (Imbernón, 2010) apontam esse modelo como o principal responsável pelo insucesso dos investimentos em formação de professores nas últimas reformas educacionais.

Os municípios da regiáo começaram a discutir a formação de professores de forma conjunta no ano 2000, no quadro da Regiấo Metropolitana recém- 
criada $^{9}$. A primeira ação metropolitana na área educacional, através da Câmara Temática de Educaçáo (CTE/ RMC), foi responder à exigência da LDB-96, ao exigir diploma de Ensino Superior para todos os professores do Ensino Básico. A regiáo contava com um déficit aproximado de 3.500 professores sem diploma na rede dos 19 municípios. Para enfrentar esta situação, foi assinado um convênio com a Reitoria da Unicamp e desenvolveu-se um programa especial de formaçáo inicial de professores - Proesf - que continha duas propostas: um curso especial de pedagogia para professores em exercício nas redes municipais e um projeto de criação de centros de formaçáo continuada. $\mathrm{O}$ curso foi um sucesso, tendo formado mais de 2.000 professores; manteve-se no formato presencial, pois a equipe da Unicamp tinha como objetivo se opor a um contexto de proliferaçáo desmedida e inconsistente de cursos a distância, que, em geral, acabam comprometendo a qualidade da formaçáo do estudante.

Já a discussão sobre Centros de Formação Continuada chegou a um impasse entre os municípios, diante de duas possibilidades: a criação de um único centro de formação regional ou de centros municipais autônomos.

Posteriormente a 2006, a questão da formação continuada de professores deixou de ser um problema metropolitano e passou a ser enfrentado isoladamente por cada sistema. A partir deste ponto do texto, procura-se compreender as estratégias municipais para oferta de formação continuada na RMC.

\section{Os modelos de provisão de formação continuada na RMC}

As múltiplas situaçóes "realmente existentes" surpreendem o observador, e, assim, os conceitos de público versus privado tornam-se insuficientes para conduzir a pesquisa. Nos primeiros contatos com as realidades municipais, verificou-se uma multiplicidade de formas e iniciativas sendo desenvolvidas; já foi assinalada a fragilidade conceptual para definir as açôes que se desenvolvem no interior dessas categorias, sendo a mais complexa aquela introduzida pelo PDRE/95 como "pública não estatal". A fragilidade de conceitos como "terceiro setor" ou "terceira via" podem estar na origem dessa polissemia.

O movimento histórico de desestatização em benefício da sociedade e dos movimentos sociais apresenta uma tênue fronteira com o processo contrário da estatização crescente desses movimentos e o da crescente estatização/judicialização das relaçóes sociais mais íntimas. Essa dificuldade leva à utilização errônea desses conceitos na discussão do tema. Uma parte importante dos movimentos sociais, que se engaja na gestão estatal, passa por transformaçôes institucionais para adequar-se à "seletividade" estatal que procura garantir a reprodução das

9 A RMC foi criada pela Assembleia Legislativa de São Paulo pela Lei Complementar 870, de junho de 2.000 . 
relaçôes de produção e as condiçóes de legitimação do sistema. Já as organizaçôes não governamentais com maior capacidade de açáo junto ao Estado precisam distanciar-se das formas ou das manifestaçôes da sociedade não aceitas (escolhidas) pela institucionalidade estatal.

Apesar da fragilidade conceitual para este campo e procurando analiticamente seu aperfeiçoamento, apresentam-se a seguir algumas observaçóes sobre a oferta de formação continuada de professores nos municípios da RMC.

Para uma primeira observação, utiliza-se provisoriamente o seguinte ordenamento:

- Iniciativa do setor público estatal

— Iniciativa do setor privado mercantil

— Iniciativa do setor privado não mercantil

— Iniciativa pública não estatal

Essa conceitualização tem utilidade apenas para início do trabalho; no entanto, o esforço principal será superar suas limitaçóes para avançar em direção a categorias de maior efetividade analítica. A Tabela 5 oferece os dados.

Tabela 5 - RMC - Formação continuada de professores em municípios selecionados $-2009^{10}$

\begin{tabular}{|l|l|l|l|l|l|}
\hline \multicolumn{1}{|c|}{ Município } & \multicolumn{1}{|c|}{ FCP } & Pública estatal & \multicolumn{1}{|c|}{$\begin{array}{c}\text { Pública não } \\
\text { estatal }\end{array}$} & Privada mercantil & \multicolumn{1}{|c|}{$\begin{array}{c}\text { Privada não } \\
\text { mercantil }\end{array}$} \\
\hline Americana & Oferta SME & $\begin{array}{l}\text { MEC (Pro } \\
\text { Letramento Mat) } \\
\text { MEC (Pro } \\
\text { Letramento } \\
\text { Port) }\end{array}$ & $\begin{array}{l}\text { MEC/Instituto } \\
\text { Airton Sena } \\
\text { (correção de } \\
\text { fluxo) }\end{array}$ & $\begin{array}{l}\text { Fundação } \\
\text { Lehman (Gestão) }\end{array}$ \\
\hline Artur Nogueira & Oferta SME & $\begin{array}{l}\text { MEC } \\
\text { SME }\end{array}$ & & Xadrez & \\
\hline Campinas & CFCP & $\begin{array}{l}\text { MEC } \\
\text { SEED.SP } \\
\text { SME } \\
\text { UNICAMP }\end{array}$ & $\begin{array}{l}\text { Francês } \\
\text { Italiano }\end{array}$ & $\begin{array}{l}\text { CENPEC } \\
\text { (Leitura) }\end{array}$ \\
\hline Cosmópolis & SME & SME & $\begin{array}{l}\text { SEED.SP Sistema } \\
\text { Ler e Escrever } \\
\text { SME }\end{array}$ & $\begin{array}{l}\text { Sistema OPT } \\
\text { Inglês } \\
\text { MindLab Brasil } \\
\text { (Projeto) }\end{array}$ & \\
\hline $\begin{array}{l}\text { Engenheiro } \\
\text { Coelho }\end{array}$ & SME & MEC (Proinfo) & $\begin{array}{l}\text { MEC/Instituto } \\
\text { Alfa Beta } \\
\text { (correção de } \\
\text { fluxo) }\end{array}$ & $\begin{array}{l}\text { Terra Viva } \\
\text { (Educação } \\
\text { infantil) }\end{array}$ & Petrobras \\
\hline Holambra & SME & &
\end{tabular}

I0 Uma relação com o significado das siglas encontra-se no final do artigo, antes da bibliografia utilizada. 


\begin{tabular}{|c|c|c|c|c|c|}
\hline Município & $\mathrm{FCP}$ & Pública estatal & $\begin{array}{l}\text { Pública não } \\
\text { estatal }\end{array}$ & Privada mercantil & $\begin{array}{c}\text { Privada não } \\
\text { mercantil }\end{array}$ \\
\hline Hortolândia & SME & $\begin{array}{l}\text { MEC (Proinfo) } \\
\text { MEC (Pro } \\
\text { Letramento Mat) } \\
\text { MEC (Pro } \\
\text { Letramento } \\
\text { Port) }\end{array}$ & & $\begin{array}{l}\text { Astral Científica } \\
\text { (Ciências) } \\
\text { Assessoria } \\
\text { (Trânsito) } \\
\text { Positivo } \\
\text { (Alfabetização) }\end{array}$ & $\begin{array}{l}\text { CENPEC/ } \\
\text { Fundação } \\
\text { Volkswagen }\end{array}$ \\
\hline Indaiatuba & - & - & - & - & - \\
\hline Itatiba & $\begin{array}{l}\text { Núcleo FCP } \\
\text { SME }\end{array}$ & & & & $\begin{array}{l}\text { Instituto Airton } \\
\text { Sena/ Fundação } \\
\text { Nívea (jovem) } \\
\text { Instituto Avila lá } \\
\text { (letramento) }\end{array}$ \\
\hline Jaguariúna & SME & & & $\begin{array}{l}\text { Positivo } \\
\text { Núcleo } \\
\text { (matemática) } \\
\text { Instituto } \\
\text { Singularidade }\end{array}$ & Renovias \\
\hline Monte Mor & SME & & PCJ (ambiental) & $\begin{array}{l}\text { Triani Assessoria } \\
\text { (FCP) }\end{array}$ & $\mathrm{CCR}$ \\
\hline Nova Odessa & SME & $\begin{array}{l}\text { UFSCar } \\
\text { Unicamp } \\
\text { UnB }\end{array}$ & & & CCR \\
\hline Paulínia & SME & $\begin{array}{l}\text { Pro Dirige } \\
\text { Educação } \\
\text { Enep }\end{array}$ & & & \\
\hline Pedreira & $\begin{array}{l}\text { Núcleo FCP } \\
\text { SME }\end{array}$ & $\begin{array}{l}\text { MEC } \\
\text { SEED SP } \\
\text { Unicamp }\end{array}$ & & & Avisa lá (leitura) \\
\hline $\begin{array}{l}\text { Santa Bárbara } \\
\text { d'Oeste }\end{array}$ & SME & SEED SP & & $\begin{array}{l}\text { Assessoria (Ler } \\
\text { Escrever) }\end{array}$ & CCR \\
\hline $\begin{array}{l}\text { Santo Antonio } \\
\text { de Posse }\end{array}$ & SME & $\begin{array}{l}\text { SEED SP } \\
\text { Unicamp }\end{array}$ & & Positivo & \\
\hline Sumaré & CFCP & $\begin{array}{l}\text { MEC } \\
\text { SEED SP } \\
\text { Unicamp }\end{array}$ & & & $\mathrm{CCR}$ \\
\hline Valinhos & SME & $\begin{array}{l}\text { MEC } \\
\text { SEED SP } \\
\text { Unicamp } \\
\text { UFSCar }\end{array}$ & & & CCR \\
\hline Vinhedo & - & - & - & - & - \\
\hline
\end{tabular}

Fonte: Martins (20|0). Elaborada pelos autores.

Esses modelos organizam as políticas descentralizadas para oferta de formação continuada de professores na regiáo. Analisar esta realidade na RMC colocou em destaque a dificuldade que representa utilizar conceitos frágeis, polissêmicos e de origem ideológica, que levam a confundir e a tornar imprecisos análise e resultados das políticas. Para concluir, seguem algumas observaçóes: 


\section{Observações sobre a forma pública estatal}

\section{Políticas da União}

O MEC está presente com programas de formação continuada de professores na maioria dos municípios pesquisados na RMC. De forma evidente, trata-se do sistema federado mais atuante na formação continuada. A sua presença permanece centrada no processo de aprendizagem, e seus programas de alfabetização (letramento) e ensino de Português e Ciências acompanham o processo de universalização da década passada. A nova visão de formação continuada, centrada na escola do MEC e expressa no projeto Mais Educação, por exemplo, encontra-se em um estágio muito incipiente de implementação. Atinge o total das escolas do município de Campinas, como piloto, para, posteriormente, ser expandido a toda RMC.

Diante das novas exigências para formação continuada de professores, o governo federal apresentou recentemente a Plataforma Freire, que destaca fortemente as novas TIC. A maior parte da oferta de formaçáo continuada será realizada pela Unirede, constituída por 82 IES públicas, utilizando educação a distância. Nas entrevistas, vários municípios declararam já ter inscrito seus professores para participar da oferta da plataforma.

O problema encontrado para definir essas ações do MEC como "públicas" está na forma de execução, gestão e financiamento da política, embora sua formulação, seu planejamento e seus objetivos possam ser creditados à capacidade institucional e de conhecimento do Estado e sejam públicos estatais os objetivos da política. Já a sua implementação não se apresenta dessa maneira, pois sua gestáo é privada.

\section{As políticas do Estado}

O sistema apostilado estadual é a principal oferta aos municípios na RMC. Objeto de grande controvérsia, tal sistema causa desconfiança na rede estadual durante sua implantação. Projeto orientado para melhoria de qualidade do ensino, procura racionalizar o tempo de trabalho pedagógico e curricular do professor. Entre as críticas mais frequentes, encontra-se a defesa da autonomia do professor no processo de ensino. No entanto, as pesquisas informam uma aceitação por parte de setores de professores e formadores da rede. Algumas falas dos professores e gestores invocam a ideia de que centrar (centralizar) a prática pedagógica permite um melhor ordenamento do trabalho escolar.

Diante das novas exigências para a formação continuada na sua rede de escolas, a Secretaria de Estado realizou uma reforma administrativa gerencial de ampla envergadura. A implantação da Escola de Formação "Paulo Renato Costa" ocupa um lugar central nesta reforma. Apenas a leitura do Decreto 57.141, de 18 de 
julho de 2011 (São Paulo, 2011), não permite identificar os modelos que serão utilizados para formação e as parcerias pelas quais a oferta será realizada. É preciso esperar um maior tempo de implantação da política para poder avaliar seus limites e suas possibilidades. $\mathrm{O}$ texto da proposta indica que continuidade institucional e acúmulo de conhecimento incorporam às políticas de Formação Continuada maior densidade teórico-institucional e melhor possibilidade de planejamento, elementos que facilitariam a implantação de políticas públicas mais tarde.

A dificuldade encontrada para caracterizar como pública essa política dos apostilados estatais é a indução política e gerencial de uma rede (estadual) sobre a outra (municipal), com grave impacto negativo sobre a autonomia constitucional dos entes federados. No entanto, o sistema apostilado é claramente estatal na sua concepção, na execução e no seu financiamento como política pública.

\section{Políticas do Município}

Os municípios da RMC desenvolvem políticas de formação de professores sem uma articulação institucional visível e sem formas de articulação pedagógica permanente. O tema "formação docente" não aparece nas atas da Câmara Temática de Educação da RMC (2005-2010) como um tema metropolitano.

Os municípios têm essencialmente organizado sua intervenção autonomamente. Cabe destacar, entre as diversas e dispersas iniciativas, alguns aspectos centrais para este trabalho:

a) o fortalecimento municipal das estruturas institucionalizadas de formação continuada. Núcleos, coordenadores, formadores, programas, vinculando a formação continuada às condições de trabalho (carreira e salário), cresceram na regiâo. Os processos mais avançados encontram-se em municípios de grande porte e renda elevada, o que não significa que não existam experiências de valor em municípios menores e pobres.

b) a falta de coordenação curricular e cognitiva da oferta. A maioria não possui um plano de formaçáo consistente, que apresente, de um lado, os eixos temáticos norteadores da oferta e, de outro, as características de formação/ conhecimento das equipes responsáveis pela coordenação e implantaçáo destes. Quase nenhum apresenta sistemas de avaliação e desenvolvimento.

c) o aumento das parcerias mercantis e não mercantis durante o período.

Todos os municípios desenvolveram um setor responsável pela formação continuada; no entanto, somente três possuem Centro de Formação Continuada e apenas dois já implantaram Núcleos de Apoio à formação. Os municípios com longa herança institucional de formação e de grande porte apresentam programas mais bem estruturados por eixos temáticos; capacidade institucional; e conhecimento acumulado para implementar esses programas 
(Penna, 2010 ${ }^{11}$. Nos outros municípios, o peso da indução externa ou a dispersão predominam na oferta de formação.

A quase totalidade dos municípios desenvolve parcerias com o setor privado, sendo $40 \%$ com o setor mercantil e $60 \%$ e com o setor privado não lucrativo; entre estes, menos de $30 \%$ poderiam ser categorizados como públicos não estatais.

As açóes de formação pública estatal de municípios nascem e desenvolvemse num ambiente institucional pouco conhecido e muito fragilmente analisado: por esse motivo, a pesquisa dessa realidade torna-se relevante na atualidade. A compreensão da resposta pública estatal para formação continuada docente não constitui somente alternativa para a função específica educacional; mais precisamente, ela permite identificar novas formas estatais de reprodução e legitimação no capitalismo contemporâneo.

\section{Observações sobre a forma privada mercantil}

A venda e a implantação dos sistemas privados de ensino seriam a forma mais pura de confronto público estatal versus mercado no setor da educação. Os sistemas apostilados têm apresentado, na última década, uma explosiva expansão no estado de São Paulo; nos municípios da RMC, essa tendência não se confirma. Apenas dois compram sistemas privados de ensino, e somente se considerarmos os apostilados estatais-não mercantis (5 municípios) a tendência se manifesta na RMC.

Também ocorre a prestação de serviços de Assessoria em quase todos os municípios, porém de formas muito diferentes. Os serviços oferecidos são dos mais diversos tipos, e sua forma é quase sempre mercantil.

Este conceito parece não apresentar maior dificuldade para expressar a realidade.

\section{Observações sobre a forma privada não mercantil}

A característica principal desta modalidade está ligada à ação de fundaçóes empresariais públicas e privadas, que financiam as açóes. Pode-se prever que esses recursos provenham majoritariamente de incentivos fiscais ou renúncias tributárias. As fundaçōes Lheman, Nívea, Petrobras e Volkswagen estão presentes na RMC sob esse modelo de oferta. Os municípios contemplados são, indistintamente, de grande e pequeno porte e de renda alta e baixa.

Como categoria explicativa, destaca-se que as instituiçôes da sociedade civil e a açáo institucionalizada dos movimentos sociais estáo compreendidas neste conceito,

I I Refere-se, aqui, ao Centro de Formação Pesquisa e Tecnologia Cefortepe, de Campinas. Após um processo de descentralização malsucedido da formação continuada, entre 2003 e 2009, o município centralizou todas as ações de formação e desenvolveu um programa de formação continuada orientado teórica e tecnicamente; e organizou sua estrutura institucional e os recursos humanos necessários. 
o que redunda em dificuldades operativas, dado que englobar a Escola Florestan Fernandes, o Greenpeace, sindicatos e fundaçóes empresariais (Lheman, Petrobras e outras) para analisar a formulação e a implementação de políticas sociais conduz a imprecisóes analíticas graves.

\section{Observações sobre formas públicas não estatais}

Esta modalidade é, sem dúvida, a mais complexa de analisar, e a sua categorização, a mais imprecisa.

O que define esta modalidade? Pode definir-se pela característica da política implementada - se universal ou focalizada? Ou privilegiando as características de sua formulação e seu gerenciamento?

$\mathrm{Ou}$, ainda, com relação ao processo decisório utilizado (participativo ou não)? $\mathrm{Ou}$, simplesmente, pelo financiamento da política proposta?

Por exemplo, a implementação de políticas do MEC por intermédio de ONGs, como acontece com o Instituo Airton Sena ou com o Instituto Alfa Beta, na RMC, operacionalizando ambas as políticas de correção de fluxo escolar, porém, fazendose acompanhar por modelos de gestáo e informação totalmente formatados pelo setor privado e de propriedade privada mercantil (ou não), é uma situação que impóe obstáculos à categorização usada para análise, desvendando suas imprecisões. Políticas estatais descentralizadas, por organizações não governamentais privadas, sem dúvida, não abarcam todas as possíveis formas representadas pelo espectro do conceito de "público não estatal". Contrariamente, estreita a análise de muitas outras possibilidades emergentes da sociedade civil - principalmente propostas transformadoras e de ruptura que surgem permanentemente na sociedade ${ }^{12}$.

\section{Conclusão}

Superar os limites impostos pela imprecisão dos conceitos utilizados exigirá um esforço suplementar. Esse avanço deveria direcionar para dar maior precisão à matriz original: público versus privado, que fica insuficiente para análise das formas de intervençấo da sociedade e do militantismo social em prol da educação.

Porém, paralelamente à escassez de categorias, a realidade continua buscando aceleradamente um novo eixo para a relação mercado versus Estado. Observando a ação estatal nacional e regional, sobressaem duas observações:

- Na área educativa, políticas públicas estatais têm induzido o comportamento do sistema; desde que seja uma política bem constituída, percebe-se

12 Experiências em geral submetidas a um processo de seletividade estrutural do Estado capitalista, que não as incorpora como parceiras para a ação; em muitos casos, as reprime, pelo contrário. Ver Offe (1985). 
uma mudança positiva no sistema. Por exemplo: a reversão no crescimento dos professores do setor privado nacional e regional, ocasionado pelo Fundeb após 2006.

- Nos municípios, políticas públicas de formação continuada com continuidade histórica e bom desenvolvimento institucional redundam em menor espaço para o setor privado. Municípios de grande porte, com renda elevada e história institucional consolidada - por exemplo, Campinas e Americana, na RMC-, apresentaram experiências de grande interesse para esta discussão. A pesquisa no Cefortepe ${ }^{13}$ indica que este desenvolve a sua oferta de formaçáo organizada por eixos pedagógicos e cognitivos, com uma estrutura física e financeira desenvolvida e uma equipe profissional numerosa e capacitada tecnicamente; atende à demanda por formação continuada com menos uso do setor privado.

O processo de desenvolvimento de capacidade institucional e cognitiva reclama continuidade de políticas, investimento financeiro e capacitação técnica profissional; muitos municípios com estruturas fragilizadas, premidos pela sua realidade, desconhecem esse princípio e procuram, no setor mercantilizado, pacotes prontos para enfrentar seus problemas.

A articulação federativa do setor estatal transforma-se em um instrumento fundamental para o sucesso das políticas de formação continuada. $\mathrm{Na}$ RMC, a atuação individual de cada município se mostra insuficiente para disputar com o setor privado a oferta de formação docente. Fica claro que a opção por açóes individualizadas fragiliza regionalmente, criando assimetrias nas ações de formação.

Por fim, o presente estudo deixa claro que, na última década, quem assumiu efetivamente a educação básica no Brasil foram os municípios. Assim, qualquer política pública para a formação continuada de professores deverá agir necessariamente em parceria com esses entes federativos.

Siglas utilizadas na tabela 6:

CCR - Grupo CCR

CENPEC - Centro de Estudos e Pesquisas em Educação, Cultura e Ação Comunitária

CFCP - Centro de Formação Continuada de Professores

FCP - Formação Continuada de Professores

Mat. - Matemática

MEC - Ministério da Educação

13 Centro de Formação Tecnologia e Pesquisa "Milton Santos", do Município de Campinas. Ver Penna (20|0). 
PCJ - Comitês das Bacias Hidrográficas dos Rios Piracicaba, Capivari e Jundiaí e Comitê da Bacia Hidrográfica dos Rios Piracicaba e Jaguari

Port. - Português

PROINFO - Programa Nacional de Tecnologia Educacional

RENOVIAS - Renovias Concessionária S.A

SEED - Secretaria Estadual de Educação

SME - Secretaria Municipal de Educação

UFSCAR - Universidade Federal de São Carlos

UNB - Universidade de Brasília

UNICAMP - Universidade Estadual de Campinas

\section{Referências bibliográficas}

ABRAHÃO, J. Financiamento e gasto público da educação básica no Brasil e comparaçóes com alguns países da OCDE e América Latina. Educação e Sociedade, Campinas, v. 26, n. 92, p. 841-858, out. 2005. Especial.

ADRIÃO, T.; PERONI, V. (Org.). O público e o privado: novos elementos para o debate. São Paulo: Xamã, 2008.

BRASIL. Emenda Constitucional n. 19, de 04 de junho de 1998. Disponível em: <http:// www.planalto.gov.br/ccivil_03/constituicao/emendas/emc/emc19.htm>. Acesso em: $10 / 09 / 2011$.

BRASIL. INEP. Microdados do Censo dos Profissionais do Magistério da Educaçáo Básica 2003. Brasília: MEC/INEP, 2006 a.

BRASIL. INEP. Sinopse do Censo dos Profissionais do Magistério da Educação Básica 2003. Brasília: MEC/INEP, 2006b.

BRESSER-PEREIRA, L. C. (Org.). O estado em transformação. São Paulo: Editora da Unesp; Brasília: Enap, 1999.

FANFANI E.; TEDESCO J. Nuevos maestros para nuevos estudiantes. In: PREAL-BID. Maestros en America Latina: nuevas perspectivas sobre su formacion y desempeño. Santiago de Chile: PREAL, 2004.

GARCIA, C. Formaçâo de professores: para uma mudança educativa. Porto: Porto Editora, 1999.

GUIDDENS, A. O debate global sobre a terceira via. São Paulo: Editora da Unesp, 2007. HIRST, P.; THOMPSOM, G. Globalização em questão: a economia internacional e as possibilidades de governabilidade. Petrópolis, RJ: Vozes, 1998.

IMBERNÓN, F. Formação permanente do professorado: novas tendências. São Paulo: Cortez, 2009. 
MARTINS, E. Políticas públicas de formação continuada de professores na RMC: parcerias entre o público e o privado. Trabalho de conclusão de curso - Unicamp, Campinas, 2010. OFFE, C. Capitalismo desorganizado. São Paulo: Brasiliense, 1985.

OHMAE, Kenich. O novo palco da economia global: desafios e oportunidades em um mundo sem fronteiras. Porto Alegre: Bookman, 2006.

PENNA, L. Políticas públicas de formação continuada de professores: o caso de Campinas. TCC, FE-Unicamp, Campinas, 2010.

SÃO PAULO. Decreto 57.141, de 18 de julho de 2011. Reorganiza a Secretaria da Educação e dá providências correlatas. Diário Oficial do Estado de São Paulo, 19 de julho de 2011.

Recebido em 05 de janeiro de 2012 e aprovado em 06 de março de 2012. 